\title{
Perceived stress and quality of life in professional and non professional caregivers of patients with dementia
}

\author{
Arti Malhotra ${ }^{1}$ \\ ${ }^{1}$ Post graduate student, Department of Psychology, Maniben Nanavati Women’s College, Mumbai. \\ E-mail-malhotra.arti87@gmail.com
}

\begin{abstract}
Background: Profound psychological effects have been observed in caregivers of Dementia. The direct implications that fall on the caregiver such as stress and quality of life have become a large area of focus in the research involving dementia. Resent researches have been limited in shedding light on the psychological factors implicated in caregiving. The key objective of the study was to find a significant difference in the quality of life and stress between professional and non-professional caregivers of patients with dementia.

Method: 60 professional and non-professional caregivers of patients with dementia were selected for the study. They were divided into two equal groups and assessed using the WHOQOL-100 Quality Of Life scale and the PSS- 10 (Perceived Stress Scale). The results were statistically analyzed.

Results: There was a significant difference between the two groups i.e. Professional and Non Professional caregivers of dementia with respect to level of Perceived Stress $(p<0.0001)$ but no difference in Quality of Life was noted. Most existing studies conducted in this area have been limited in an Indian context. Current findings of the study can be attributed to cultural and social differences in comparison with researches from other regions.

Conclusion: The results obtained were not in line with many previous studies. Further research with consideration of various factors affecting the caregivers is warranted.
\end{abstract}

Keywords dementia, caregivers, quality of life, perceived stress, professional, non-professional

(Paper received $-17^{\text {th }}$ August 2016, Peer review completed $-30^{\text {th }}$ August 2016, Accepted $-4^{\text {th }}$ September 2016)

\section{INTRODUCTION}

"Of all the things, I miss my mind the most." This quote by renowned author Mark Twain speaks of memory loss and dementia. Dementia is a neurological disease that usually occurs after the age of 60 . It is marked by memory loss, impaired cognitive functions, compromised volition as well as changes in personality. Dementia has been deemed as a "silent epidemic" which is the single greatest cause of disability in over 65 year olds worldwide. It is estimated 35.6 million people suffer from dementia, the numbers nearly doubling every 20 years [1-2].

In severe and late stages of dementia, the individual may lose complete control over most of their functioning processes leading to a direct reliance on a caregiver. While there are many positive aspects of caring, caregivers of people with dementia are very likely to experience strain. There may also be physical health consequences - strained caregivers have impaired immunity and a higher mortality rate. Caregiving for an individual can prove to be a double edged sword. Though there are some rewards and benefits most of the time the process of care giving can prove to be highly stressful and burdensome [3]. Caregivers and those who live with people with dementia are twice as likely as others to have significant psychological illness. The caregiving process will prove to be particularly more stressful for non-professional caregivers as compared to professional caregivers. Professional caregivers will be well equipped and more immune to 
dealing with the daily pressures. Non-professional caregivers will face the brunt of added financial costs and personal relationships [4].

Alzheimer's disease robs people of their memories and their ability to think clearly, and the latest annual report from the Alzheimer's Association has placed a price tag on how the disease can rob families financially. According to the report, in 2016 an estimated total of \$236 billion will go toward treating Alzheimer's and other forms of dementia, when including the payments from the government, private insurance and out-of-pocket costs [5]. The cost of caregiving and can prove to be a significant financial burden for a caregivers, particularly, a family member. In high-income countries, the direct costs of dementia care exceed informal care costs, with the cost of institutional care in care homes dominating in this category [6]. Recent research on dementia however fails to focus on more on the psychological implications of the syndrome especially toward caregivers who are severely affected by the heavy strain and burden it brings into their life [7]. Recent researches provide a more reductionist view focusing on biological, genetic and environmental factors causing dementia. More research aimed at psychological aspects and effects will shed relevant light to this area which will help professionals, caregivers and family members to be better equipped in dealing with individuals suffering from dementia with optimal care and treatment [8]. The current study was aimed at assessing the perceived stress and quality of life between professional and non-professional caregivers of patients with dementia.

\section{METHODOLOGY}

\section{Scales used in the study}

1. Quality of Life Scale by WHO (WHOQOL-100): The scale was developed by the WHOQOL Group. The intra-rater reliability for the total WHOQOL and its subscales ranges between 0.840.93 [9].

2. Perceived Stress Scale (PSS): This test was used to measure stress in caregivers. The Cronbach's alpha reliability coefficient for the PSS is 0.89 [10].

\section{Inclusion Criteria for participants in this study}

1. Professional caregivers who have received formalized training in geriatric care, neurocognitive disorders.

2. Non - Professional caregivers who have not received any kind of formalized training in geriatric care.

3. Caregivers in each group would have spent a minimum of six months caring for the patient.

\section{Study Outline}

1. Approval of the Ethics Committee was taken prior to the commencement of the study.

2. Patients and their caregivers were informed of the research objectives and assured confidentiality of their responses. Informed consent was taken.

3. Professional and Non - professional caregivers meeting the inclusion criterion were included in the study.

4. A sample of 60 caregivers; Professional and Non - Professional were divided into two equal groups.

5. The rating scales were administered.

6. The data obtained was pooled and divided into two groups; Professional Caregivers of Dementia and Non - Professional Caregivers of Dementia

7. The data was then statistically analyzed.

\section{STATISTICAL ANALYSIS}

The entire data was analyzed using the SPSS statistical software version 19.0 and the results were presented. The independent samples $t$ tests were used for each of the variables under study. Tests for normality to assess kurtosis and skewedness of data were also done. 


\section{RESULTS}

The descriptive statistics revealed that the mean value of Perceived Stress for Professional group was 10.8 \pm 4.27 in a scale of which the possible minimum score is 10 and the possible maximum score is 40 . On the other hand, the mean value of Perceived Stress for Non-Professional group was $21.96 \pm 3.99$. There was a statistically significant difference between the professional and non professional caregivers on the $t$ test $(\mathrm{t}=15.004, \mathrm{df}=58, \mathrm{p}<0.0001)$. The mean value of Quality of Life (Psychological Factors) for Professional group was $67.03 \pm 11.71$ and the mean value of Quality of Life for the Non-Professional group was 60.43 \pm 24.82 . Comparison of the scores revealed no significant differences between the groups despite stress being higher in the non-professional group $(\mathrm{t}=1.8641, \mathrm{df}=58, \mathrm{p}=0.0648)$. (Table 1$)$

Table 1 - scores on various scales between the two groups

\begin{tabular}{|cccc|}
\hline Scales Used & $\begin{array}{c}\text { Professional } \\
\text { caregivers }\end{array}$ & $\begin{array}{c}\text { Non-professional } \\
\text { caregivers }\end{array}$ & $\begin{array}{c}\text { Statistical Analysis } \\
(\mathrm{df}-58)\end{array}$ \\
& \multicolumn{1}{c}{$(\mathrm{N}=60)($ Mean $\pm \mathrm{SD})$} & $\mathrm{t}=15.004$ \\
Perceived Stress Scale & $10.8 \pm 4.2$ & $21.9 \pm 3.9$ & $\mathrm{p}<0.0001^{*}$ \\
\hline Quality of Life Scale & $67.03 \pm 11.71$ & $60.43 \pm 24.8$ & $\mathrm{t}=1.8641$ \\
$\mathrm{p}=0.0648$
\end{tabular}

*significant $(\mathrm{p}<0.05)$ (Unpaired t test used in the assessment)

\section{DISCUSSION}

The first research assumption was; non-professional caregivers of dementia experience higher levels of stress as compared to professional caregivers of dementia. The statistical result found was not in line with the first hypothesis and also not in line with past studies [11] where results confirm previous findings of lower stress among non-professional dementia caregivers and suggests that different factors influence caregivers' appraisal of the situation, including their perception of stress, based on recipients' dementia status. Interactive factors of stress were examined by comparing a group of elderly family caregivers to a control group of non-caregiving peers. The groups were compared on their perceptions of positive and negative aspects of daily activities as well as on the relationship between these perceptions and psychological symptoms. A daily experience list, the RUCHL (Routines, Uplifts, Challenges, and Hassles List), and the HSCL (Hopkins Symptom Checklist) were administered to each respondent. A buffering effect of positive experiences did not emerge; positive score did not interact with negative scores, nor did they interact with group membership in predicting overall psychological symptoms. Caregivers rated greater negative impact in everyday experiences than did non-caregivers, whether or not experiences directly related to caregiving were included. The ratings of positive impact were higher than for negative impact and were similar in both groups. Negative impact scores predicted psychological symptoms for both groups, whereas positive impact scores did not. Thus, previous studies indicate that stress plays a critical and vital role for caregivers of dementia [12-13]. The second research assumption was professional caregivers of dementia will have a higher quality of life as compared to non-professional caregivers of dementia. The statistical result obtained was not in line with the hypothesis and also not in line with previous studies [14-15] that show that a significant relationship exists between quality of life and caregivers of dementia. Quality of life has observed to be poorer in caregivers of Dementia according to past researches and studies. In an Indian context, the society being more collectivist as compared to a western one, extended social and domestic support may provide a possible explanation for the above research findings. Individual and personality variables may also play a crucial aspect toward the caregiving process. Socio economic factors are considered important and contributing factors for family caregivers of dementia. Many confounding factors may influence the findings of our study and detailed explorations into this facet of professional and non-professional caregivers in dementia via future studies are warranted. 


\section{REFERENCES}

1. Larson EB, Yaffe K, Langa KM. New insights into the dementia epidemic. New Eng J Med 2013;369(24):2275-7.

2. Ferri CP, Prince M, Brayne C, Brodaty H, Fratiglioni L, Ganguli M, Hall K, Hasegawa K, Hendrie H, Huang Y, Jorm A. Global prevalence of dementia: a Delphi consensus study. Lancet 2006;366(9503):2112-7.

3. Pinquart M, Sörensen S. Helping caregivers of persons with dementia: which interventions work and how large are their effects?. Int Psychogeriatr 2006;18(04):577-95.

4. Etters L, Goodall D, Harrison BE. Caregiver burden among dementia patient caregivers: a review of the literature. J Am Acad Nurs Pract 2008;20(8):423-8.

5. Aguilar SC. A systematic review to assess the policy-making relevance of dementia cost-of-illness studies in the US and Canada. Pharmacoeconomics 2011;29(2):141-56.

6. Langa KM, Chernew ME, Kabeto MU, Regula Herzog A, Beth Ofstedal M, Willis RJ, Wallace RB, Mucha LM, Straus WL, Fendrick AM. National estimates of the quantity and cost of informal caregiving for the elderly with dementia. J Gen Intern Med 2001;16(11):770-8.

7. Brodaty H, Donkin M. Family caregivers of people with dementia. Dialog Clin Neurosci 2009;11(2):217-28.

8. Connell CM, Janevic MR, Gallant MP. The costs of caring: Impact of dementia on family caregivers. J Geriatr Psychiatr Neurol 2001;14(4):179-87.

9. Group TW. The World Health Organization quality of life assessment (WHOQOL): development and general psychometric properties. Soc Sci Med 1998;46(12):1569-85.

10. Cohen S, Kamarck T, Mermelstein R. A global measure of perceived stress. J Health Soc Behav 1983;1:38596.

11. Schulz R, Martire LM. Family caregiving of persons with dementia: prevalence, health effects, and support strategies. Am J Geriatr Psychiatry 2004;12(3):240-9.

12. Dunkin JJ, Anderson-Hanley C. Dementia caregiver burden A review of the literature and guidelines for assessment and intervention. Neurology 1998;51(1 Suppl 1):S53-60.

13. Belle SH, Burgio L, Burns R, Coon D, Czaja SJ, Gallagher-Thompson D, Gitlin LN, Klinger J, Koepke KM, Lee CC, Martindale-Adams J. Enhancing the quality of life of dementia caregivers from different ethnic or racial groups: a randomized, controlled trial. Ann Internal Med 2006;145(10):727-38.

14. Thomas P, Lalloué F, Preux PM, Hazif-Thomas C, Pariel S, Inscale R, Belmin J, Clément JP. Dementia patients caregivers quality of life: the PIXEL study. Int J Geriatr Psychiatry 2006;21(1):50-6.

15. Riedijk SR, De Vugt ME, Duivenvoorden HJ, Niermeijer MF, Van Swieten JC, Verhey FR, Tibben A. Caregiver burden, health-related quality of life and coping in dementia caregivers: a comparison of frontotemporal dementia and Alzheimer's disease. Dementia Geriatr Cogn Disord 2006;22(5-6):405-12.

\footnotetext{
Acknowledgements - Nil

Source of Funding - Nil

Conflict of Interest - Nil
} 